\title{
Efektifitas Papan Petunjuk Berbahasa Arab
}

\author{
Zaqiatul Mardiah, Ulfa Ana Maria \\ Program Studi Sastra Arab, Fakultas Sastra, \\ Universitas Al Azhar Indonesia, Jl. Sisingamangaraja, Jakarta 12110 \\ Penulis untuk Korespondensi/E-mail: zaqiah@uai.ac.id
}

Abstrak - Saat ini, signage-signage di Indonesia, terutama di bandara ditulis dalam empat bahasa, yaitu bahasa Indonesia, bahasa Inggris, bahasa Mandarin, dan bahasa Arab. Fenomena penambahan bahasa Arab pada signage adalah sesuatu yang menarik untuk diamati lebih jauh, mengingat ada cukup banyak wisatawan yang berasal dari negeri Arab yang datang ke Indonesia. Penelitian ini diupayakan untuk dapat menjawab seputar penggunaan bahasa Arab pada papan petunjuk itu, antara lain; mengkaji keberterimaan penggunaan bahasa Arab tersebut oleh para wisatawan baik dari segi diksi, maupun kaidah gramatikalnya, dan mendeskripsikan aspek sintak-semantis bahasa Arab pada papan petunjuk itu. Melalui pendekatan kualitatif dan metode analisis yang deskrptif, diperoleh hasil yang menyatakan bahwa signage yang berupa kata atau frasa, pada tataran struktur lahir (surface structure) adalah sebuah kalimat minor yang unsur subjeknya dilesapkan guna efisiensi dan efektifitas, serta readibilitas sebuah signage. Kalimat yang lengkap, yang ada unsur subjek dan predikatnya justru muncul pada struktur batin (deep structure)nya. Unsur subjek yang dilesapkan tersebut adalah pronomina demonstrativa. Pada signage yang berupa kalimat, jika ditinjau dari struktur lahir dan struktur batin, tidak mengalami perbedaan seperti pada signage kata atau frasa. Dari sudut pandang semantis, makna yang muncul pada setiap signage adalah makna denotatif, Adapun dari analisis kesalahan penulisan dan ketepatan pemilihan kata, diperoleh kesimpulan bahwa sebagian signage sudah benar penulisannya dan sudah tepat pilihan katanya. Namun, ada sebuah kesalahan gramatika dan pemilihan diksi, yang ditemukan pada signage 2; dan ada pula penyampaian sebuah bentuk larangan yang menurut responden kurang tepat secara kultural.
Abstract - Nowadays, signage-signage in Indonesia, especially in airports is written in four languages, namely Indonesian, English, Chinese, and Arabic. The phenomenon of the addition of Arabic on the signage is something that is interesting to observe further, considering there are quite a lot of tourists from Arab countries who came to Indonesia. This study attempted to answer about the use of Arabic on the user board, include; assess the acceptability of the use of the Arabic language by the tourists both in terms of diction, as well as grammatical rules, and describes the syntaxsemantic aspects of Arabic on the user board. Through qualitative approach and descriptive analysis method, obtained results stating that the signage in the form of words or phrases, at the level of the surface structure is a minor sentence elements omitted subject to the efficiency and effectiveness, as well as a signage readibilitas. Complete sentences, that there are elements of the subject and the predicate it appears on the inner structure (deep structure) it. Element omitted subject is a pronoun demonstrativa. On signage in the form of the sentence, if the terms of the surface structure and inner structure, do not experience the difference as the signage word or phrase. From the point of view of semantic, meaning that appear in any signage is denotative, As of the writing error analysis and accuracy of the choice of words, the conclusion that most of the signage is correct writing and word choice are correct. However, there is a grammatical error and selection of diction, which is found on the signage 2; and there is also a ban on the delivery of a form according to respondents less culturally appropriate.

Keyword: Signage, Deep Structure, Surface structure 


\section{PENDAHULUAN}

$\int_{\text {ignage adalah salah satu bentuk komunikasi }}$ khususnya tanda visual. Dalam kamus Oxford Advance Learner Dictionary of Current English [1], Signage didefinisikan dengan sebuah kata atau kata-kata dan lain-lain pada sebuah papan atau lempengan untuk memberi peringatan atau untuk mengarahkan seseorang menuju sebuah tempat. Dalam konteks kegiatan pariwisata, semua yang dipaparkan sebelumnya itu menjadi aspek-aspek yang sangat dibutuhkan. Signage atau papan petunjuk menjadi kebutuhan utama bagi para wisatawan. Dengan adanya signage, kegiatan para wisatawan menjadi terbantu. Mereka menjadi lebih leluasa dan merasa nyaman dengan keberadaan signage, apalagi jika bahasa yang digunakan dalam signage adalah bahasa negara mereka.

Saat ini, signage-signage di Indonesia, terutama di bandara ditulis dalam empat bahasa, yaitu bahasa Indonesia, bahasa Inggris, bahasa Mandarin, dan bahasa Arab. Bahasa Arab mulai dipakai dalam tulisan signage di bandara diperkirakan mulai tahun 2000-an. Sebelumnya, hanya ada tulisan berbahasa Inggris dan bahasa Indonesia. Fenomena penambahan bahasa Arab pada signage adalah sesuatu yang menarik untuk diamati lebih jauh, mengingat ada cukup banyak wisatawan yang berasal dari negeri Arab yang datang ke Indonesia.

Wawancara singkat pernah dilakukan dengan 5 wisatawan timur tengah. Mereka menyambut baik kebijakan pemerintah Indonesia menambahkan bahasa Arab pada signage di bandara. Bahkan, mereka berharap, signage yang demikian tidak hanya ditambahkan di bandara, tapi juga di tempat-tempat pariwisata dan hotel. Mereka mengaku sangat senang dan nyaman dengan keberadaan papan petunjuk yang ditulis dalam bahasa mereka yakni bahasa Arab. Berikut ini adalah salah satu contoh signage dalam bahasa Arab di bandara.

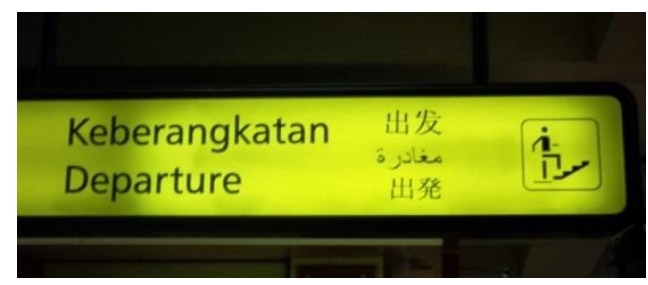

Gambar 1. Signage dalam bahasa arab di bandara
Berdasarkan wawancara, mereka menyebutkan bahwa ada beberapa tulisan pada signage yang menurut mereka menyalahi kaidah gramatikal; ada pula yang pilihan katanya kurang tepat, dan lainlain. Pernyataan tersebut menjadi daya tarik untuk melakukan kajian yang lebih mendalam terhadap signage atau papan petunjuk berbahasa Arab yang ada di Jakarta. Tidak hanya sisi gramatikal yang akan dicermati, tapi juga keberterimaan dan keterbacaan signage tersebut bagi wisatawan Timur Tengah. Hal ini erat kaitannya dengan diksi yang tepat serta efektifitas signage tersebut sebagai public sign yang membantu wisatawan untuk berkatifitas dengan nyaman.

Penelitian ini diupayakan untuk dapat menjawab seputar penggunaan bahasa Arab pada papan petunjuk di beberapa tempat yang biasa dikunjungi para wisatawan. Secara detail, penelitian yang diusulkan memiliki beberapa tujuan, yaitu:

1. Mengkaji keberterimaan penggunaan bahasa Arab oleh para wisatawan baik dari segi diksi, maupun kaidah gramatikalnya.

2. Mendeskripsikan karakter bahasa Arab pada papan-papan petunjuk.

3. Mendeskripsikan kaidah gramatikal bahasa Arab pada papan petunjuk

\section{KERANGKA TEORI}

\section{Signage \\ Signage atau /la:fitah/ menurut Oxford Advance Learner Dictionary Of Current English adalah sebuah kata atau kata-kata, desain, dan lain-lain pada sebuah papan untuk memberikan peringatan atau untuk mengarahkan seseorang menuju sesuatu. Menurut Lawrence K.Frank, arti signage adalah pesan atau informasi yang muncul dan menimbulkan respon pada manusia [2].}

Penggunaan signage sebagai alat untuk menyampaikan informasi kepada orang lain harus mempertimbangkan berbagai aspek yang membuat signage dapat disesuaikan dan berfungsi dengan baik. Di antara syarat-syarat signage adalah pertama, kemudahan signage untuk dilihat orang. Kedua, tulisan pada signage dapat dibaca secara jelas, dan informasi yang disampaikan dapat dengan mudah dimengerti. Bahkan mungkin dalam hitungan detik, pengguna dapat dengan mudah membaca dan menangkap maksudnya.

Dilihat dari fungsinya, signage adalah (1) media komunikasi yang membantu manusia dengan cara 
mengarahkan, mengidentifikasi ruang atau struktur dan memberi informasi kepada manusia dalam melakukan kegiatan dalam suatu ruang; (2) memperkuat kualitas lingkungan secara visual; dan (3) melindungi kepentingan umum.

Secara umum, Signage dapat dikategorikan menjadi enam yaitu; pemberi orientasi (Orientational Sign), pemberi informasi (Informational Sign), pemberi indentitas (Identificational Sign), penunjuk arah (Directional Sign), pemberi peringatan (Statutory Regulatory Sign), pemberi dekorasi (Ornamental Sign) [2].

\section{Sintaksis}

Sintaksis dalam bahasa Arab (ilmu nahwu) adalah ilmu yang membahas kaidah yang digunakan untuk mengetahui tataran sebuah kalimat dalam bahasa Arab. Setiap kalimat tersusun dari beberapa kata, yang mempunyai arti, yang dapat menunjukkan kedudukan dari kata tersebut di dalam kalimat. Dalam bahasa Indonesia, itu dikenal dengan istilah SPO (subjek, predikat dan objek); begitu pun halnya dalam bahasa Arab. Sintaksis adalah ilmu yang mempelajari hubungan antara kata, frasa, klausa, kalimat yang satu dengan kata, frasa, klausa, dan kalimat yang lain [3]. Kata, frasa, klausa, dan kalimat inilah yang disebut sebagai satuan sintaksis. Tulisan pada signage sudah pasti merupakan satuan sintaksis. Dengan pisau analisa sintaksis, masing-masing satuan itu akan diamati secara mendalam, baik sebagai sebuah satuan maupun hubungannya dengan satuan lain dalam sebuah konstruksi. Dalam hal yang terakhir disebutkan, fungsi dan kategori sintaksislah yang berperan menjadi alat analisisnya.

Dalam analisa sintaksis, ada dua istilah yang tidak boleh dilupakan, yaitu deep Structure (struktur batin) dan surface Structure (struktur lahir). Struktuk batin dapat diartikan sebagai struktur yang mendasari kalimat atau kelompok kata, yaitu mengandung semua informasi yang diperlukan untuk interpretasi sintaksis dan semantik kalimat dan tidak dinyatakan secara langsung dari sebuah kalimat atau kelompok kata [4]. Struktur lahir merupakan struktur yang tampak. Dalam bahasa Indonesia dapat pula disebut struktur luar.

\section{Semantik}

Kata "semantik" disepakati sebagai istilah yang digunakan untuk bidang linguistik yang mempelajari hubungan antara tanda-tanda linguistik dengan hal-hal yang ditandainya.
Dengan kata lain, semantik adalah bidang studi dalam linguistik yang mempelajari makna atau arti bahasa [5]. Padanannya dalam bahasa Arab adalah ilmu al-dillalah yang berasal dari kata دل-يدل - دلالة Idalla - yadullu - dilalah/ yang berarti 'menunjukkan' [6]. Hidayatullah dkk., menyebutkan bahwa semantik memperlajari makna satuan-satuan lingual bahasa, yaitu kata, frasa, klausa, dan kalimat [3]. Sementara Fromkin dan Rodman menyebut kajian makna kata dan hubungan makna antarkata sebagai semantik leksikal, sedangkan kajian makna unit sintaksis yang lebih besar daripada kata disebut semantik frasal dan semantik kalimat [7]. Oleh Cruse, dua jenis semantik yang terakhir disebut sematik gramatikal [8].

Ada beberapa jenis makna dalam kajian linguistik, yaitu:

Makna Leksikal (معنى أساسى / ma'na asasi)

Makna leksikal yaitu jenis makna yang memberikan makna hakiki dari suatu kata. Chaer menjelaskan makna leksikal sebagai makna yang sesuai dengan referennya, makna yang sesuai dengan observasi panca indra atau makna yang sungguh-sungguh nyata dalam kehidupan kita [5].

\section{Makna Gramatikal (معنى غير أساسى) ma'na goiru asasi)}

Makna gramatikal ini sering juga disebut makna kontekstual atau makna situasional [5]. Selain itu, makna jenis ini dapat juga disebut makna struktural, karena proses dan satuan-satuan gramatikal itu selalu berkenaan dengan struktur ketatabahasaan. Makna gramatikal adalah makna yang hadir sebagai akibat adanya proses gramatika seperti proses afiksasi, proses reduplikasi, dan proses komposisi. Contoh : sate ayam tidak sama dengan komposisi sate Madura, yang pertama menyatakan 'asal bahan' dan yang kedua menyatakan 'asal tempat).

\section{Diksi}

Diksi atau pilihan kata adalah:

1. Pilihan kata atau diksi mencakup pengertian kata-kata yang akan dipakai untuk menyampaikan suatu gagasan, bagaimana membentuk pengelompokan kata atau menggunakan ungkapan-ungkapan yang tepat.

2. Pilihan kata atau diksi adalah kemampuan membedakan secara tepat tentang makna dari gagasan yang ingin disampaikan, dan kemampuan untuk menemukan bentuk yang sesuai dengan situasi dan nilai rasa yang 
dimiliki oleh suatu kelompok pendengar/ penerima.

3. Pilihan kata yang tepat dan sesuai hanya dimungkinkan oleh penguasaan sejumlah kosakata atau perbendaharaan kata bahasa itu [9].

Menurut Kridalaksana diksi adalah pilihan kata dan kejelasan lafal untuk memperoleh efek tertentu dalam berbicara di depan umum atau dalam karangan [4].

Dalam Kamus Besar Bahasa Indonesia diksi adalah pilihan kata yang tepat dalam penggunaannya, untuk mengungkapkan gagasan sehinga diperoleh sesuai yang diharapkan [10]. Jadi, dapat disimpulkan bahwa diksi adalah pilihan kata yang tepat untuk mewakili buah pikiran atau gagasan seseorang. Ada dua syarat dalam memilih kata, yaitu ketepatan memilih kata dan kesesuaian pilihan kata.

\section{Ketepatan memilih kata}

Ketepatan memilih kata mempersoalkan sebuah kata dapat menimbulkan gagasan/ide yang tepat pada imajinasi pembaca atau pendengar, seperti yang dipikirkan atau dirasakan penulis/pembaca. Ketepatan dalam memilih kata dalam hal ini, menyangkut masalah makna dan kosakata [3]. Beberapa cara atau solusi agar bisa mencapai ketepatan pilihan kata [3], sebagai berikut.

1. Membedakan secara cermat denotasi dan konotasi.

2. Membedakan kata-kata yang hampir bersinonim. Kata-kata yang bersinonim tidak selalu memiliki distribusi yang saling melengkapi.

3. Membedakan kata-kata yang mirip dalam ejaannya.

4. Hindari kata-kata ciptaan sendiri.

5. Waspadalah terhadap penggunaan akhiran asing.

\section{Kesesuaian Pilihan Kata}

Persoalan kedua dalam pendayagunaan kata-kata adalah kecocokan/ kesesuaian. Perbedaan antara ketepatan pertama-tama mencakup soal kata mana yang akan digunakan dalam kesempatan tertentu walaupun terkadang masih ada perbedaan tambahan berupa perbedaan tata bahasa, pola kalimat, panjang/kompleksnya sebuah alinea dan beberapa segi lain.

Kesesuain diksi mempermasalahkan apakah pilihan kata dan gaya bahasa yang dipergunakan tidak merusak suasana atau menyinggung perasaan orang yang hadir. Ada beberapa hal yang diperlukan agar kata yang digunakan tidak mengganggu suasana dan tidak menimbulkan ketegangan antara penulis atau pembicara dengan pendengar atau pembaca.

Jadi secara singkat perbedaan antara persoalan ketepatan dan kesesuaian adalah dalam persoalan ketepatan kita bertanya apakah pilihan kata yang kita gunakan sudah setepat-tepatnya, sehingga tidak akan menimbulkan interpretasi yang berlainan antara pembicara dengan pendengar atau antara penulis atau pembaca, sedangkan dalam persoalan kesesuaian yang kita persoalkan adalah apakah pilihan kata dan gaya bahasa yang dipergunakan tidak merusak suasana/ menyinggung perasaan orang lain [9].

\section{METODE PENELITIAN}

Analisa yang akan dilakukan dalam penelitian ini, menggunakan data sekunder yang berasal dari kata, frasa, dan kalimat berbahasa Arab yang tertera pada papan-papan petunjuk di bandara, hotel dan beberapa tempat pariwisata di ibu kota Jakarta. Ada 20 signage atau papan petunjuk yang diperoleh di bandara dan hotel tersebut. Adapun efektifitas penggunaan bahasa Arab akan dijelaskan secara kualitatif berdasarkan informasi yang diperoleh dari para wisatawan Timur Tengah. Dalam kurun waktu tiga hingga empat bulan telah dijaring 15 wisatawan secara acak, baik di bandara, hotel, maupun tempat-tempat pariwisata lainnya. Informasi dari para wisatawan tersebut akan menjadi data tentang keberterimaan diksi dan kaidah gramatikal bahasa Arab yang terdapat pada papan petunjuk.

Data kebahasaan akan dikaji dengan menggunakan metode deskriptif, berdasarkan kaidah sintaksemantik bahasa Arab seperti yang tertera pada Landasan Teori. Sementara data yang berupa informasi dari wisatawan akan dijaring dengan cara wawancara dan observasi; yang kemudian akan dipaparkan secara kualitatif.

Penelitian ini bertujuan untuk menjawab pertanyaan-pertanyaan riset sebagai berikut:

1. Apakah pilihan kata yang digunakan dalam papan petunjuk itu tepat dan sesuai dengan maksud yang diinginkan oleh pembuat papan itu dan berterima bagi wisatawan? 
2. Bagaimana kaidah gramatikal, masing-masing papan petunjuk tersebut?

3. Apakah papan petunjuk itu cukup membantu para wisatawan untuk beraktifitas?

Analisis data yang akan dilakukan dibagi menjadi beberapa tahap. Pertama, mengelompokan data yang termasuk dalam satuan sintaksis bahasa Arab yaitu; kata, frasa, dan klausa/kalimat. Kedua, menganalisis data berdasarkan kaidah sintaksis dan semantis yaitu dari segi satuan sintaksis, fungsi, dan kategori. Ketiga, menkonfirmasi data kepada para turis Timur Tengah yang menjadi responden, baik dari segi diksi, maupun kesahihan gramatikal. Tahap terakhir adalah menyimpulkan hasil analisis data agar dapat diketahui bagaimana tataran sintaksis dan semantik kosakata bahasa Arab dalam bidang pariwisata; dan diketahui pula keberterimaan bahasa Arab pada papan petunjuk tersebut di kalangan turis Timur Tengah.

\section{HASIL DAN PEMBAHASAN}

Ada 20 signage atau papan petunjuk yang diperoleh dari bandara dan hotel di Jakarta. 20 papan petunjuk tersebut diklasifikasi berdasarkan satuan sintaksis tulisan yang ada padanya, yaitu yang berupa kata, frasa, dan kalimat.

1. Satuan sintaksis kata: 5 signage

2. Satuan sintaksis frasa: 10 signage

3. Satuan sintaksis kalimat: 5 signage

Data tersebut sengaja dikelompokkan berdasarkan satuan sintaksisnya, sehingga tidak semua data harus dianalisis, tetapi hanya yang mewakili masing-masing satuan tersebut. Itu dilakukan karena analisis untuk satuan yang sama, misalnya kata, tidak berbeda. Artinya, jika semua signage yang berupa kata (ada 5) disajikan analisisnya, akan terjadi penjelasan yang berulang; dan itu akan membosankan. Oleh karena itu, masingmasing satuan akan diambil satu signage untuk disajikan analisisnya dalam bab ini.

\section{Signage Kata}

Ditinjau dari kacamata sintaksis, pada tataran surface structure (struktur lahir), signage (Gambar. 2) bertuliskan sebuah kata. Namun, jika ditinjau lebih dalam, satuan sintaksis مغادرة / muga:darah / tidak hanya berupa kata, melainkan sebuah kalimat minor. Seperti yang sudah disajikan dalam sub bab Kerangka Teori, kalimat minor adalah kalimat yang tidak ada subjek atau predikatnya [11].

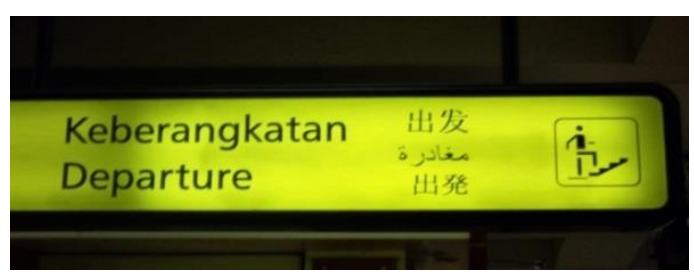

Gambar 2. Signage 1 (signage kata)

Secara umum, kumpulan kata dapat disebut sebuah kalimat, apabila setidaknya terdiri dari subjek dan predikat. Dalam konteks signage di atas, ada konstituen kalimat yang sengaja dilesapkan yaitu subjek. Subjek yang dilesapkan itu adalah pronomina demonstrativa, yang dalam bahasa Arab disebut ism isyarah. Ism isyarah yang menjadi subjek dalam signage di atas boleh jadi هذ /hazihil 'ini', atau boleh jadi pula /huna:/ 'di sini. Pronomina demontrativa هذ ه ه /hazihil atau /huna:/ sengaja tidak dimunculkan dalam signage agar membuat signage lebih efektif, efisien dan mudah dibaca. Dengan demikian, pada hakikatnya pada tataran deep structure (struktur batin), signage di atas berbunyi:

هذه مغادرة /hazihi muga:darah/ 'ini (tempat) pemberangkatan' (Deep Structure) ; atau

P S

مغادرة /huna: muga:darah/ 'di sini (tempat) pemberangkatan'

Jika hendak ditinjau dari kaca mata semantik, kata pada signage tersebut mengandung makna denotatif, yaitu makna dasar kata seperti yang tertera dalam kamus. Dalam kamus, maknanya adalah keberangkatan. Akan tetapi, dalam konteks ini, sebenarnya pihak Angkasa Pura ingin memberitahu banyak orang bahwa "di sinilah tempat pemberangkatan". Fenomena ini dapat disebut sebagai makna asosiatif yang timbul dari tulisan signage yang berupa kata itu.

Berikutnya, kata /muga:darah/ dikonfirmasi kepada wisatawan Timur Tengah. Hasilnya menyebutkan bahwa tulisan dan pilihan kata yang dipakai pada signage 1 sudah tepat menurut mereka. Mereka menjelaskan, bahwa kata yang sama juga tertera pada signage di bandara negara mereka. Untuk memperkuat pernyataan tersebut, dilakukan penelusuran website dan gambar signage مغادرة /muga:darah/ di search engine google. Ternyata kata مغادرة /muga:darah / sudah benar dan tepat dari segi penulisan maupun pemilihan katanya. 


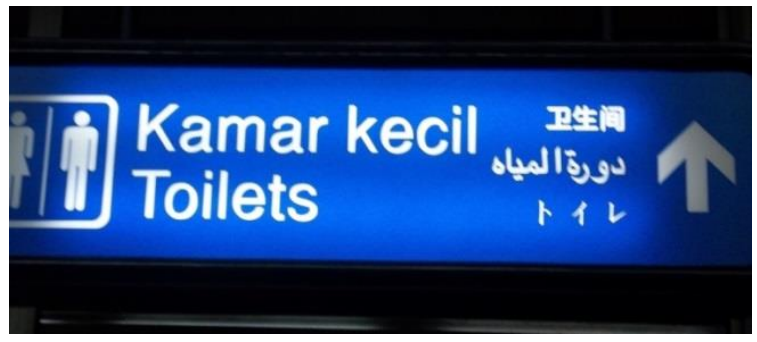

Gambar 3. Signage 2 (signage frasa)

\section{Signage Frasa}

Tulisan pada signage (Gambar 3) terdiri dari dua kata yang membentuk sebuah frasa, yaitu frasa nominal. Disebut demikian karena kata pertama /dawrah/ berupa nomina, dan kata kedua /miya:h/ juga berupa nomina, yang membentuk kesatuan makna. Dalam bahasa Arab, kata دورة /dawrah/ berfungsi sebagai mudhof dan kata المياه / almiya: $h /$ berfungsi sebagai mudhof ilaih [12].

Pada signage 2, kajian sintaksisnya tidak jauh berbeda dengan kajian pada signage sebelumnya. Disebut begitu, karena keduanya pada tataran deep structure merupakan kalimat yang terdiri dari subjek dan predikat; bukan kata atau frasa seperti yang terlihat pada surface structure.

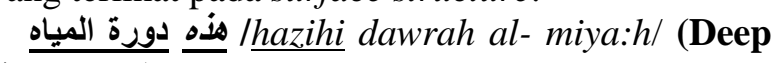
Structure)

$\mathrm{P} \quad \mathrm{S}$

\section{/dawrah al- miya:h/ \\ Structure)}

(Surface

Perbedaan signage (Gambar 2) dan signage (Gambar 3) terletak pada kategori sintaksis yang mengisi fungsi predikat. Pada signage 1, fungsi

predikat diisi nomina /muga:darah/, sedangkan pada signage 2, fungsi predikatnya diisi oleh frasa nominal /dawrah al miya:h/ yang terdiri dari nomina /dawrah/dan nomina /almiya: $h /$.

Secara semantis, frasa pada signage 2 tidak bermakna denotatif. Di dalam kamus, makna kata دورة /dawrah/ adalah 'putaran'. Adapun dalam Hans Wehr [8], makna kata دورة /dawrah/ adalah 'area atau kawasan', sedangkan kata دورة المياه lal- miya:h/ memiliki makna dasar 'air'. Ketika bergabung menjadi frasa, kedua kata itu bermakna 'putaran air' atau ' kawasan air'. Makna yang demikian tentu tidak mudah untuk dikaitkan langsung dengan toilet atau kamar mandi. Dalam konteks ini, 'putaran air atau kawasan air' yang dimaksud adalah tempat yang biasanya banyak terdapat air, dan air tersebut mengalami daur atau perputaran, mengalir dari satu tempat ke tempat yang lain. Dengan keterangan yang demikian, makna itu dapat dipadankan dengan kamar mandi yang memang di dalamnya ada "air yang berputar". Dalam KBBI, kamar mandi diberi arti kamar tempat mandi [10]. Selain itu, ada padanan lain yang juga turut disebutkan, seperti jamban, wc dan kamar kecil.

Padanan dalam bahasa Indonesia yang ditulis pada signage adalah kamar kecil. Kamar kecil bukanlah kamar yang kecil, tetapi 'jamban, tempat buang air kecil [10]. Frasa 'kamar kecil' lebih dipilih dalam signage karena dinilai sesuai dengan konteksnya yaitu berada di tempat umum yang fungsi utamanya adalah tempat untuk buang air. Alasan lain adalah 'kamar kecil' dinilai lebih sopan dari kata 'wc' atau 'jamban' karena konteks penempatannya di area bandara.

Dari segi diksi, menurut para native speaker yang menjadi responden, sudah tepat dan biasa digunakan di negara asal mereka. Namun, ada salah satu responden yang menyatakan bahwa penulisan frasa pada signage 2 di bandara Soekarnoe-Hatta itu sedikit mengalami kesalahan, khususnya pada kata /dawrah/yang berbentuk kata tunggal, dan kata kedua yang definit. Ia menyebutkan bahwa tulisan /dawrah/ yang benar adalah dalam bentuk plural, yaitu /dawra:t/, dan kata keduanya tidak diawali artikel definit /al/. Keterangan tersebut diperkuat oleh penelusuran di search engine google. Pada penelusuran tersebut ditemukan sebuah gambar signage yang bertuliskan دورات مياه dawra:t miya:h/ (Gambar 4).

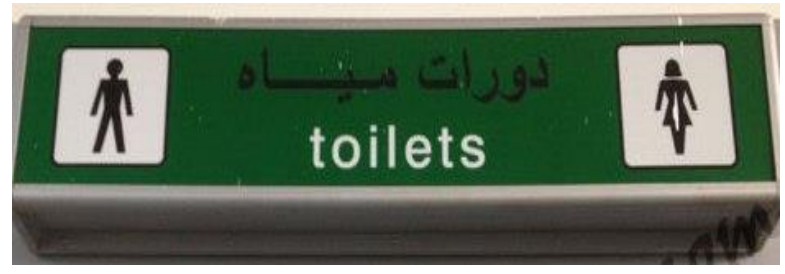

Gambar 4. Signage pada toilet [13]

\section{Signage Kalimat}

nasykuru kum li 'adami al-tadkhin fi hazihi al- man'iqah/ (Signage 3)

Apabila signage 3 ditinjau pada tataran surface structure, satuan sintaksisnya adalah kalimat fi'liyah, yaitu kalimat yang diawali fi'l atau verba [2] [11]. 


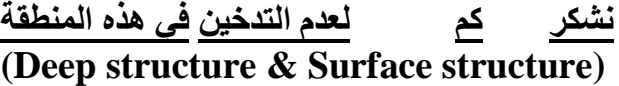 \\ Frs prep Frs Prep Pron VPron \\ Ket tempat Ket keadaan $\quad \mathbf{O} \quad \mathbf{P}+\mathrm{S}$}

Apa yang terlihat pada struktur lahir, tidak berbeda dengan maksud yang ada pada struktur batin. Artinya, tidak ada pelesapan konstituen kalimat, seperti yang terjadi pada signage 1 dan 2 . Kalimat yang ditulis pada signage yang diperoleh di hotel ini, disampaikan apa adanya sesuai dengan keinginan pihak hotel.

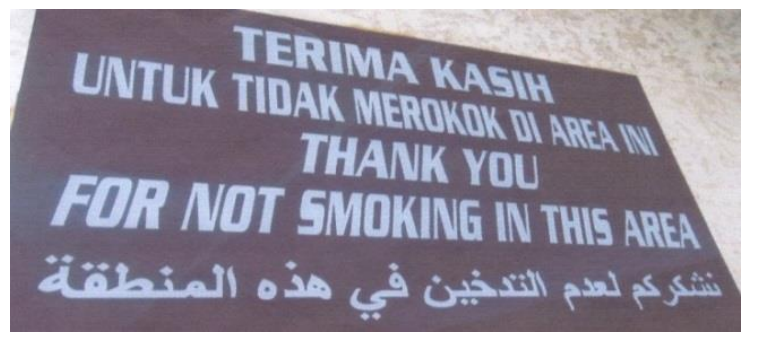

Gambar 5. Signage 3 (signage kalimat)

Jika ditelusuri segi semantisnya, makna yang terkandung dalam signage 3 adalah makna denotatif atau makna seperti yang ada dalam kamus.

نشكر /nasykurul 'kami berterima kasih'

S / $/ \mathrm{kum} /$ '(kepada) anda'

(لعدم التخين / li 'adami al-tadkhin/ 'untuk tidak ada (kegiatan) merokok'

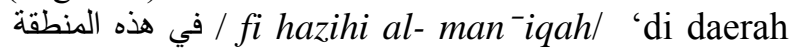
ini'

Secara keseluruhan maknanya adalah 'Kami berterima kasih kepada anda untuk tidak merokok di daerah ini'. Tampaknya, tulisan pada signage ini lebih condong untuk mengikuti kultur Indonesia. Dalam budaya Indonesia, hal yang sangat lumrah untuk menyampaikan sebuah larangan atau perintah dalam bentuk kalimat afirmatif.

PERHATIAN

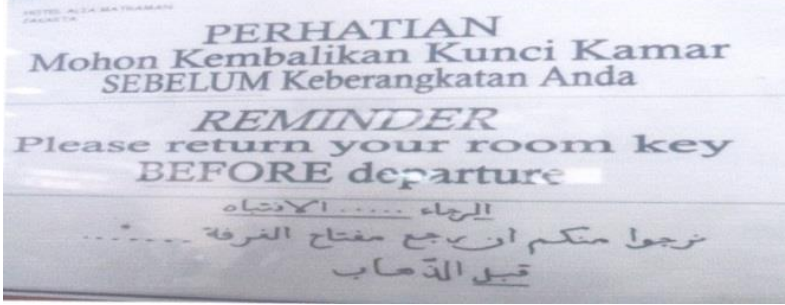

Gambar 7. Signage 4 (signage kalimat)
Bentuk kalimat larangan atau kalimat perintah akan dianggap orang Indonesia sebagai perilaku yang kasar dan tidak memiliki sopan santun. Dengan alasan itulah, pihak hotel yang memang warga negara Indonesia menulis signage tersebut dalam bentuk kalimat afirmatif deklaratif. Ada contoh kalimat lain pada signage di hotel, yang juga memperlihatkan struktur penyampaian larangan atau perintah dalam kalimat afirmatif.

Bentuk pragmatis dari signage 3 dan 4 yang dianggap mengikuti kultur Indonesia diperkuat oleh pernyataan dari responden tamu hotel yang berasal dari Timur tengah. Mereka menerangkan bahwa tidak ditemukan kesalahan dalam penulisan signage 3. Akan tetapi, terdapat ketidakapikan dalam penyampaian larangan. Menurut mereka, larangan merokok tidak perlu disampaikan dalam kalimat yang panjang seperti itu. Ada sebuah frasa dengan maksud yang sama, yang banyak ditemukan di negara Arab yaitu ممنوع التنخين / mamnu:' al- tadkhî:n / 'dilarang merokok'. Gambar berikut adalah salah satu signage di negara Arab yang menyatakan larangan merokok itu.

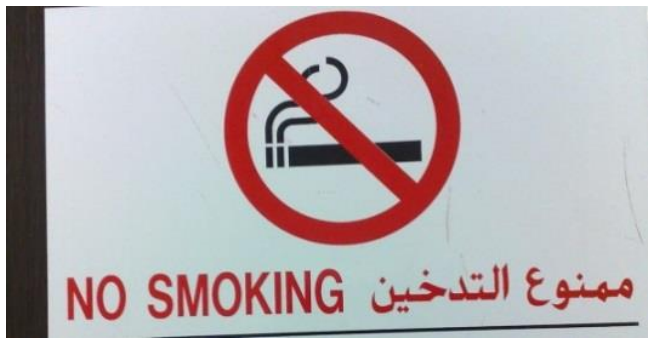

Gambar 8. Signage larangan merokok [14]

Adapun signage 4, secara gramatika terdapat kesalahan pada kata setelah /an/. Setelah partikel /an/ harusnya diisi verba mudhari' /tura:ji'a/, bukan nomina /raj'a/. Selain itu, salah seorang responden menjelaskan bahwa tulisan tersebut akan menjadi lebih baik apabila diganti dengan tulisan berikut.

النرجو اعادة مفتخ الغرفة قبل الذهاب Inarju i'a:dah mifta:h al-gurfah qabla al-ziha:b/.

\section{KESIMPULAN}

Dalam penelitian ini, ditemukan 20 signage atau papan petunjuk berbahasa Arab. Tiga belas signage di bandara dan tujuh signage terdapat di hotel. Semua signage tersebut telah dianalisis 
berdasarkan sudut pandang sintaksis, semantik dan diksi.

Berdasarkan kajian sintaksis, papan petunjuk tersebut diklasifikasi menjadi tiga, yaitu lima signage berbentuk kata, sepuluh berbentuk frasa dan lima berbentuk kalimat. Signage yang berbentuk kata dan frasa, pada tataran deep structure (struktur batin) adalah sebuah kalimat nominal yang terdiri dari subjek dan predikat. Subjeknya berupa pronomina demonstrativa, sedangkan predikatnya adalah kata atau frasa yang ada pada signage itu. Adapun pada tataran surface structure (struktur lahir), tulisan pada signage yang berupa kata atau frasa itu adalah kalimat minor yang subjeknya (pronomina demonstrativa) sengaja dilesapkan guna keefektifan kalimat itu sebagai sebuah papan petunjuk.

Signage yang berupa kalimat, jika ditinjau dari struktur lahir dan struktur batin, tidak mengalami perbedaan seperti pada signage kata atau frasa. Apa yang disajikan pada tataran struktur lahir, itulah yang dimaksud pada tataran struktur batin. Dari sudut pandang semantis, makna yang muncul pada setiap signage adalah makna denotatif, yaitu makna yang tertera di dalam kamus. Adapun dari analisis kesalahan penulisan dan ketepatan pemilihan kata, diperoleh kesimpulan bahwa kata pertama pada signage 2 lebih tepat ditulis dalam bentuk plural. Selain itu, kata kedua-nya harus dalam bentuk indefinit (taktarkrif) tanpa artikel /al/. Sementara pada signage kalimat, hasil penelusuran dengan responden menyimpulkan bahwa kalimat pada signage yang menyatakan larangan merokok, seharusnya tidak disampaikan dalam bentuk kalimat yang panjang; tetapi cukup dengan sebuah frasa /mamnu:'u al tadkhi:n/ 'dilarang merokok'

Dari segi efektifitas dan keberterimaan makna, para responden menyebutkan bahwa papan petunjuk tersebut sangat efektif membantu mereka di Indonesia. Namun, mereka sangat menyayangkan keberadaan signage berbahasa
Arab yang hanya ada di bandara Soekarno-Hatta dan 2 hotel di Jakarta. Mereka berharap, pemerintah Indonesia membuat signage berbahasa Arab pada tempat-tempat pariwisata dan hotelhotel lainnya dalam jumlah yang lebih banyak.

\section{DAFTAR PUSTAKA}

[1]. A.S. Hornby. 2010. Oxford Advance Learner Dictionary of Current English. England: OUP .

[2]. Suryantini, Rini. 2001. Sign and Signage System. Skripsi Sarjana, tidak diterbitkan. Depok: Universitas Indonesia.

[3]. Hidayatullah, Moch. Syarif dan Abdullah. 2010. Pengantar Linguistik Bahasa Arab (Klasik Modern). Jakarta: Universitas Islam Negeri (UIN) Sharif Hidayatullah Yakarta.

[4]. Kridalaksana, Harimurti. 2002. Struktur, Kategori, dan Fungsi dalam Teori Sintaksis. Jakarta : Universitas Katolik Indonesia Atma Jaya.

[5]. Chaer, Abdul. 2009. Pengantar Semantik Bahasa Indonesia. Jakarta : Rineka Cipta.

[6]. Hans Wehr. 1974. A Dictionary of Modern Written Arabic. Beirut: Librarie du Liban.

[7]. Fromkin, Victoria. Robert Rodman. Nina Hyams 2011. An Introduction to Language. USA. Wadsworth.

[8]. Cruse, D.A.. 1986. Lexical Semantics. Australia: CUP.

[9]. Keraf, Gorys. 2007. Diksi dan Gaya Bahasa. Jakarta: Gramedia.

[10]. Departemen Pendidikan Nasional. 2008. Kamus Besar Bahasa Indonesia Pusat Bahasa. Jakarta: Gramedia.

[11]. Alwi, Hasan dll. 2000. Tata Bahasa Baku Bahasa Indonesia (edisi ke-3). Jakarta: Balai Pustaka.

[12]. Al-Ghulayini, Syeikh Mustafa. 2007. Jami'u AdDurusi Al-'Arabiyyati. Beirut : Darul Fikri.

[13]. http://www13.0zz0.com/2013/01/11/11/77892185 9.jpg

[14]. http://1.bp.blogspot.com/xwRhNVuk3FA/T39mF KB3q9I/AAAAAAAACXM/PAy70LD8gFU/s16 00/010220125030.jpg

[15]. Sutanti. 2008. Analisis Teks Informasi Lalu Lintas di Wilayah Surakarta. Skripsi Sarjana, tidak diterbitkan . Surakarta: Universitas Muhammadiyah Surakarta. 